\title{
Bulk Photovoltaic Effect in a Pair of Chiral-Polar Layered \\ Perovskite-Type Lead Iodides Altered by Chirality of Organic Cations
}

Po-Jung Huang, ${ }^{\dagger}$ Kouji Taniguchi, ${ }^{* \dagger, *}$ and Hitoshi Miyasaka*†,*

$\dagger$ Department of Chemistry, Graduate School of Science, Tohoku University, 6-3 Aramaki-Aza-Aoba, Aoba-ku, Sendai 980-8578, Japan

$\$$ Institute for Materials Research, Tohoku University, 2-1-1 Katahira, Aoba-ku, Sendai 980-8577, Japan

* Corresponding author:

Hitoshi Miyasaka

Institute for Materials Research, Tohoku University, 2-1-1 Katahira, Aoba-ku, Sendai 980-8577, Japan

Tel: $+81-22-215-2030$

Fax: +81-22-215-2031

e-mail: miyasaka@,imr.tohoku.ac.jp 


\section{EXPERIMENTAL SECTION}

Materials. All reagents were commercially available and were used as received without further purification.

Synthesis of $(\boldsymbol{R}-\mathrm{MPA})_{2}(\mathrm{MA}) \mathrm{Pb}_{2} \mathbf{I}_{7}(\boldsymbol{R}-\mathbf{1})$ and $(\boldsymbol{S} \text {-MPA })_{2}(\mathbf{M A}) \mathrm{Pb}_{2} \mathbf{I}_{7}(\boldsymbol{S}-\mathbf{1}) . \mathrm{PbO}(2.232 \mathrm{~g}, 10$ mmol) was dissolved in hot $57 \% \mathrm{HI}$ solution $\left(10 \mathrm{~mL}, 130{ }^{\circ} \mathrm{C}\right)$ followed by addition of $2.8 \mathrm{~mL}$ of $50 \% \mathrm{H}_{3} \mathrm{PO}_{2}$ solution. The boiling yellow solution was kept stirring for 5 min until fully dissolution after $\mathrm{MACl}(338 \mathrm{mg}, 5 \mathrm{mmol})$ was added. Black precipitates were dissolved at $150{ }^{\circ} \mathrm{C}$ until the solution turned yellow, followed by the treatment of $(R)$ - or $(S)-\beta$-methylphenethylamine (946 mg, $7 \mathrm{mmol}$ ) in $5 \mathrm{~mL}$ of $\mathrm{HI}$, which was prepared at $0{ }^{\circ} \mathrm{C}$ in advance. The resulting yellow solution allowed stirring for $5 \mathrm{~min}$ after boiling and was then cooled down from $100{ }^{\circ} \mathrm{C}$ to room temperature with rate of $2{ }^{\circ} \mathrm{C} /$ day. Millimeter-sized red plate-shaped crystals were obtained with a yield of about $30 \%$. (Hastening cooling rate will lead to smaller crystals) Anal. Calcd. (found) for $\mathrm{C}_{19} \mathrm{H}_{34} \mathrm{I}_{7} \mathrm{~N}_{3} \mathrm{~Pb}_{2}$ (R-1): C 14.20 (14.73), H 2.13 (2.32), N 2.61 (2.55)\%; (S-1): C 14.20 (14.74), H 2.13 (2.24), N $2.61(2.72) \%$. Selected IR data (observed in KI-pellets, $\mathrm{cm}^{-1}$ ) for $(\boldsymbol{R}-1): 3060(\mathrm{~m}), 3019(\mathrm{~m})$, 2962(m), 2905(w), 2876(w), 1567(s), 1493(m), 1453(s), 1390(w), 986(m), 963(m), 906(w), 869(w), 829(w), 755(s), 697(s), 643(w), 594(w), 546(m), 531(m); (S-1): 3068(m), 3013(m), 2964(m), 2881(w), 1564(s), 1492(m), 1461(s), 1389(w), 1014(w), 989(m), 962(m), 907(m), 869(w), 827(w), 757(s), 699(s), 638(w), 589(w), 545(m), 526(m).

X-ray crystallography. Suitable size of single-crystals of $\boldsymbol{R}-\mathbf{1}$ and $\boldsymbol{S}-\mathbf{1}$ were selected for single-crystal X-ray diffraction analysis. Data were collected at $103 \mathrm{~K}$ on a CCD diffractometer (Rigaku Saturn 724) with a multilayer mirror and monochromated Mo K $\alpha$ radiation $(\lambda=0.71075$ $\AA$ ). Space group and crystal parameters of both compounds hardly change at $293 \mathrm{~K}$, indicating no structural phase transition between 103 and $293 \mathrm{~K}$. Thin Kapton films were used for the measurements. Refinement of cell parameters and data reduction were performed with the CrysAlisPro software package. ${ }^{1}$ Crystal structures were solved by direct methods $(\operatorname{SIR} 2011)^{2}$ and refined using the CrystalStructure crystallographic software package with full-matrix least-squares 
$F^{2}$ values. $^{3}$ All non-hydrogen atoms were refined anisotropically. Organic hydrogen atoms were placed in ideal, calculated positions with isotropic thermal parameters located on the respective carbon atoms that are not partially occupied. The axis direction of single crystals was determined on the CrystalClear software package. ${ }^{4}$ Crystallographic data for $\boldsymbol{R}-\mathbf{1}$ (CCDC-1936623) and $\boldsymbol{S}-\mathbf{1}$ (CCDC-1936624) are summarized in Table S2. X-ray powder diffraction (XRPD) patterns were recorded using a Rigaku Ultima IV diffractometer with $\mathrm{Cu} \mathrm{K} \alpha$ radiation $(\lambda=1.5418 \AA)$ at room temperature (Figure S12).

Physical property measurements. Infrared (IR) spectra were recorded as KI pellets with a JASCO FT/IR-4200 spectrometer. Optical absorption spectra in ultraviolet-visible (UV-VIS) region were measured on KI pellets using a spectrophotometer JASCO V-770. Circular dichroism (CD) spectra were measured using spin coated thin film sample of $\boldsymbol{R} \mathbf{- 1}$ and $\boldsymbol{S} \mathbf{- 1}$ from concentrated DMSO solution with a JASCO J-1500 MIF CD spectrometer at room temperature.

Photocurrent measurements. Photocurrent was measured by DC two-probe method with a semiconductor parameter analyzer (Agilent B1500A) connected to a probe station (Riko-boeki). Light irradiation was conducted by a solar simulator XES-40S3 combining xenon lamp of power of 150 W. Filters 400, 480, 550, 600, and $730 \mathrm{~nm}$ were used for checking light wavelength dependence of photocurrent. The light power on sample were measured by an THORLABS optical power meter PM100D equipped with an energy sensor, where about 16 and $0.6 \mathrm{~kW} / \mathrm{m}^{2}$ were detected with and without filter, respectively. Electrodes were attached on the single crystals by carbon paste.

Computational details. Density functional theory (DFT) calculations with a Gaussian basis set were performed for organic cations $R-\mathrm{MPA}^{+}$and $\mathrm{MA}^{+}$. The B3LYP/6-31G+(d) level of theory was used and all calculations were conducted using Gaussian09.5 


\section{RACEMIC COMPOUND}

By applying a racemic $\mathrm{MPA}^{+}$cation in the synthesis, we also obtained a racemic compound, rac-1 for attempt of comparison with chiral compounds. Although the crystal quality was not good enough for single-crystal structural analysis, we confirmed that rac-1 crystallizes in a different structure from those of $\boldsymbol{R} \mathbf{- 1}$ and $\boldsymbol{S} \mathbf{- 1}$ by comparing XRPD patterns (Figure S12) and cell parameters from single-crystal X-ray diffraction patterns (Table S2).

Photocurrent measurements were carried out for rac-1 under the same conditions for $\boldsymbol{R}-\mathbf{1} / \boldsymbol{S}-\mathbf{1}$. Figure S13 shows the measurement configuration of $I-V$ curves, in which the crystallographic [010] direction is placed parallel or perpendicular to the applied electric field. For rac-1, no zero-bias photocurrent is observed in both configurations (Figure 4). 


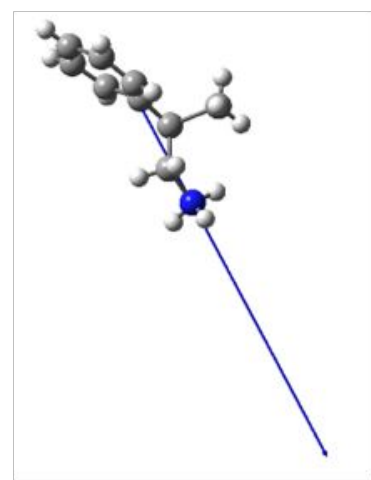

$(R)-\mathrm{MPA}^{+}(1): 12.540$ Debye

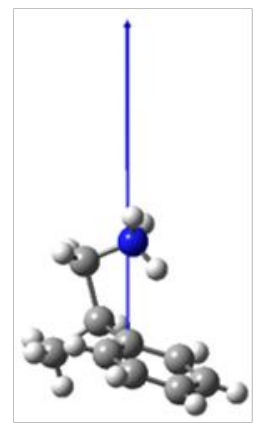

$(R)-\mathrm{MPA}^{+}(4): 9.101$ Debye

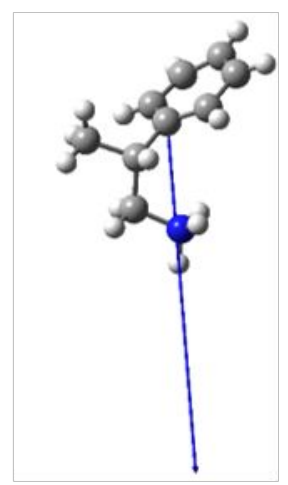

$(R)-\mathrm{MPA}^{+}(2): 9.712$ Debye

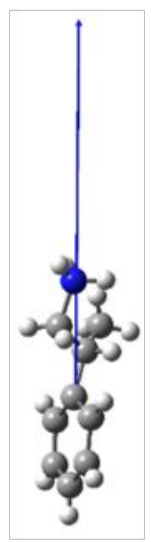

$(R)-\mathrm{MPA}^{+}(5): 11.671$ Debye

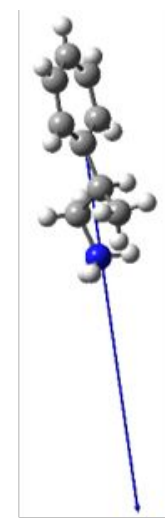

$(R)-\mathrm{MPA}^{+}(3): 11.361$ Debye

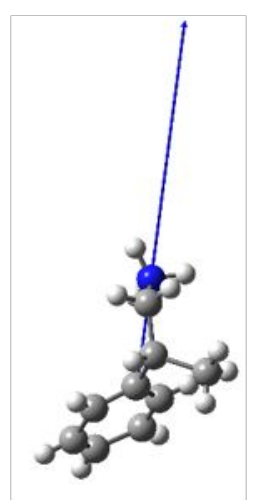

$(R)-\mathrm{MPA}^{+}(6): 10.251$ Debye

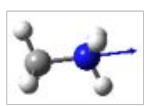

$\mathrm{MA}^{+}: 2.735$ Debye

Figure S1. Calculated electric dipole moments for the six unique $(R)-\mathrm{MPA}^{+}$and one $\mathrm{MA}^{+}$organic cations using atom coordinates obtained from the crystal structure of $\boldsymbol{R}-\mathbf{1}$. The blue arrows indicate the direction of electric dipole moment with color codes $\mathrm{C}$ (gray), $\mathrm{N}$ (blue), $\mathrm{H}$ (white). 


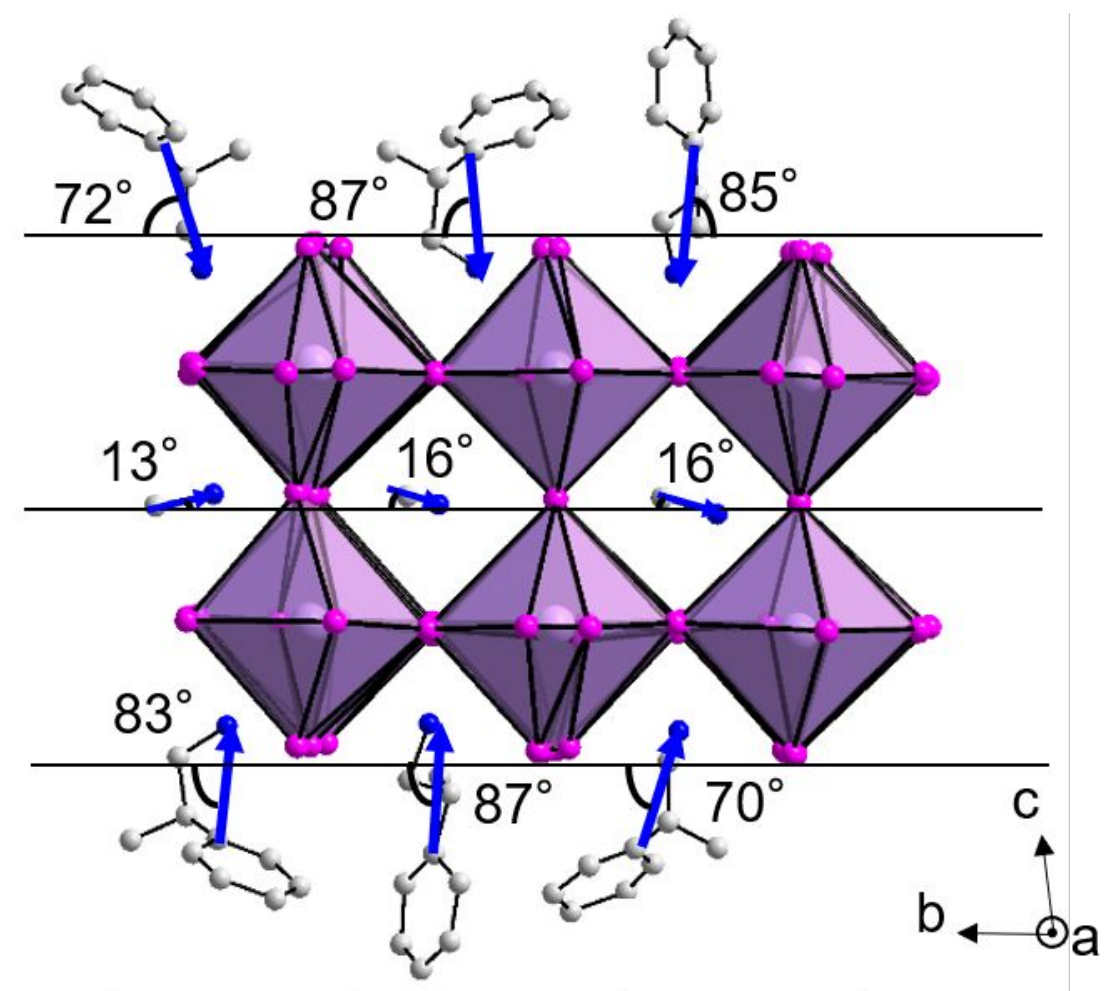

Figure S2. Calculated electric dipole moments of the organic species in $\boldsymbol{R}-\mathbf{1}$ shown in the blue arrows with color codes: $\mathrm{Pb}$ (lavender), I (pink), $\mathrm{C}$ (gray), $\mathrm{N}$ (blue). The electric polarization of 1.06 $\mu \mathrm{C} \mathrm{cm}^{-2}\left(0.54\right.$ and $0.52 \mu \mathrm{C} \mathrm{cm}^{-2}$ from $(R)-\mathrm{MPA}^{+}$and $\mathrm{MA}^{+}$, respectively) nearly parallel to [010] is estimated (angle between $\boldsymbol{P}_{\mathbf{m}}$ and $b$-axis $\left(/ a b\right.$-plane) is $3.84^{\circ}\left(/ 3.83^{\circ}\right)$ ). 


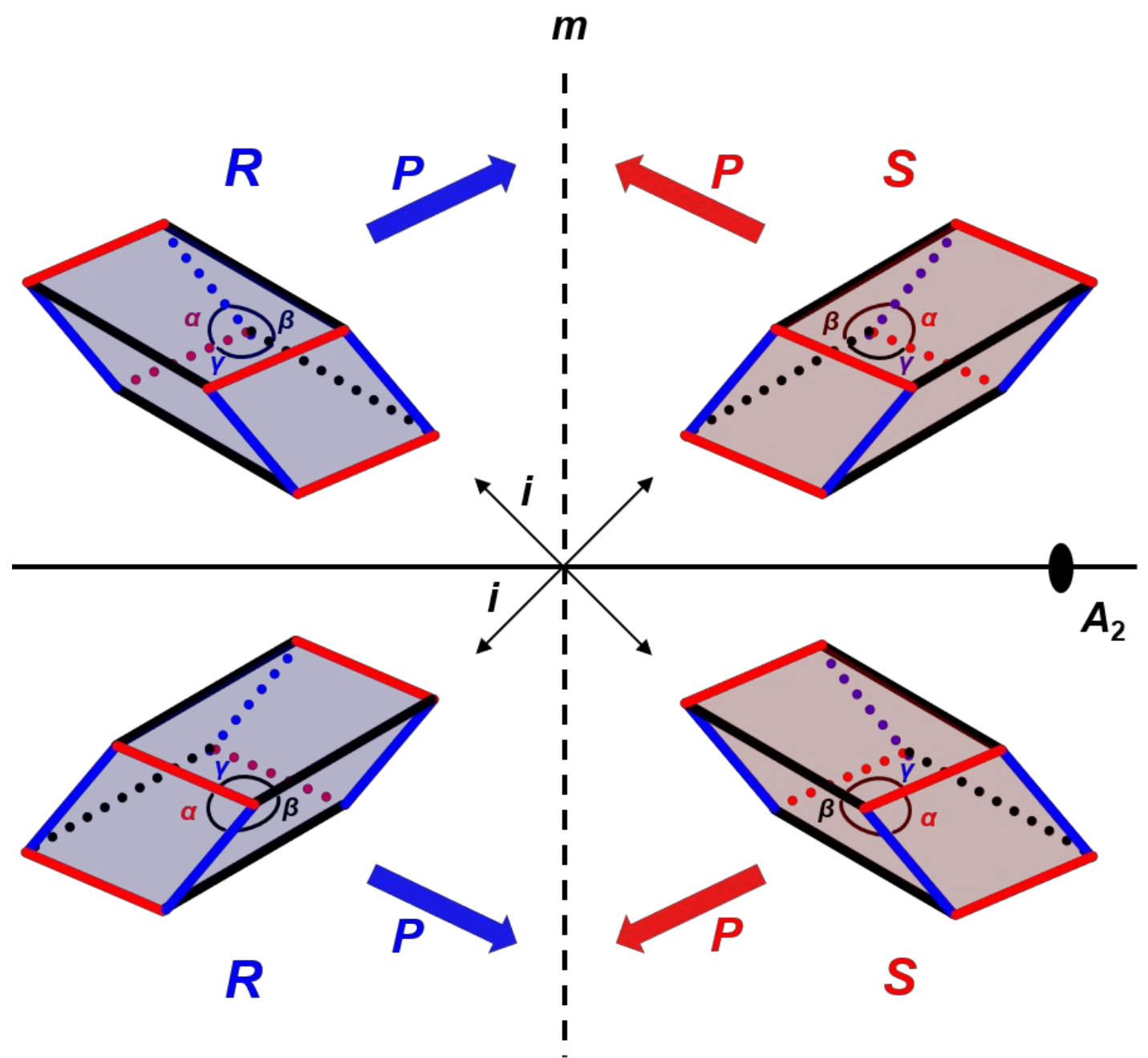

Figure S3. Correlation between chirality and polarity under reflection $(m)$, two-fold axis rotation $\left(A_{2}\right)$, and inversion $(i)$ operations. Only inversion operation converts the enantiomers in the same crystal coordinates allowing comparison of the electric polarization $(\boldsymbol{P})$. 


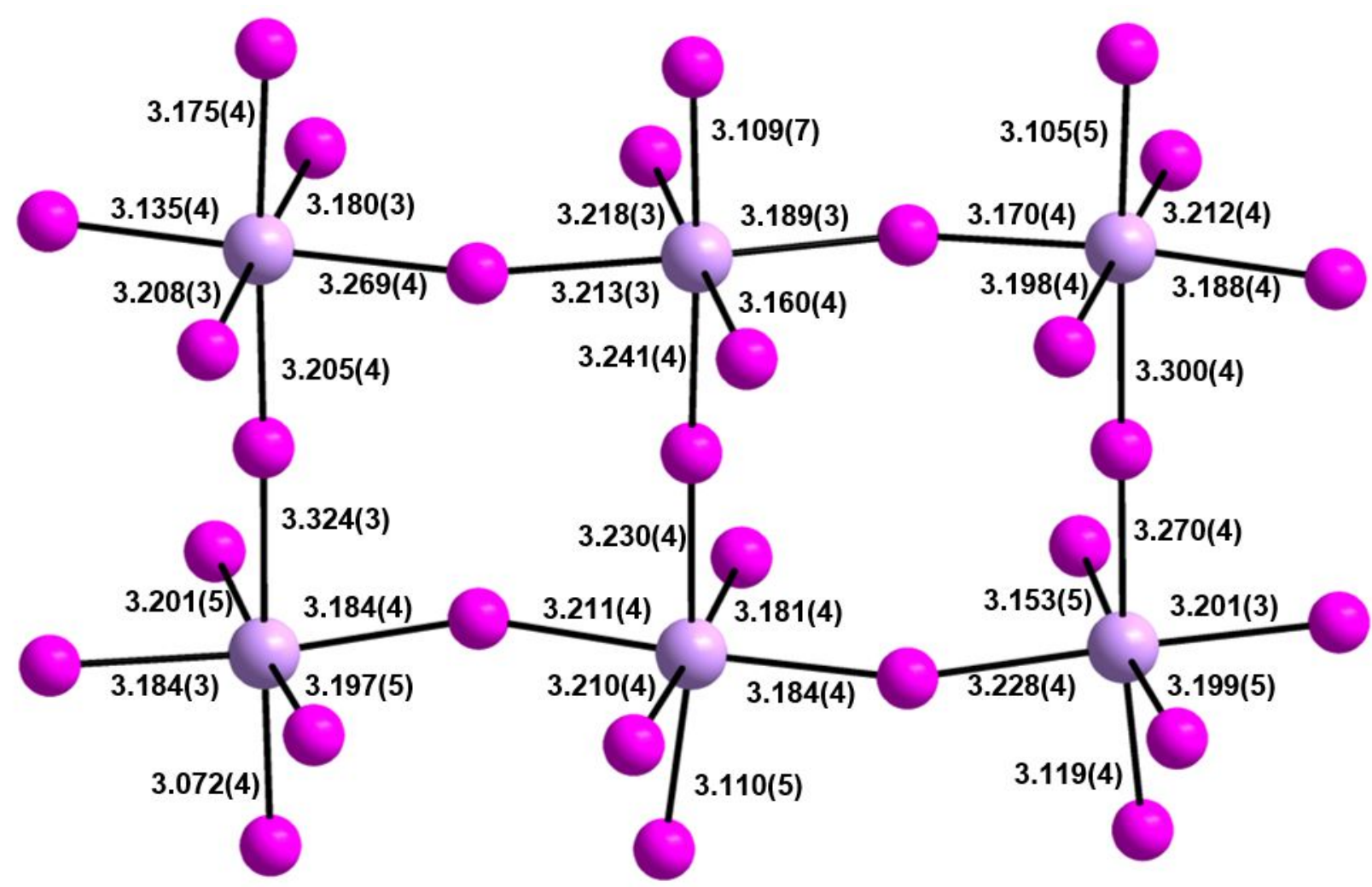

Figure S4. $\mathrm{Pb}-\mathrm{I}$ bond lengths (in $\AA$ ) of the six unique $\mathrm{PbI}_{6}$ octahedra in $\boldsymbol{R}-\mathbf{1}$. Color codes: $\mathrm{Pb}$ (lavender), I (pink). 


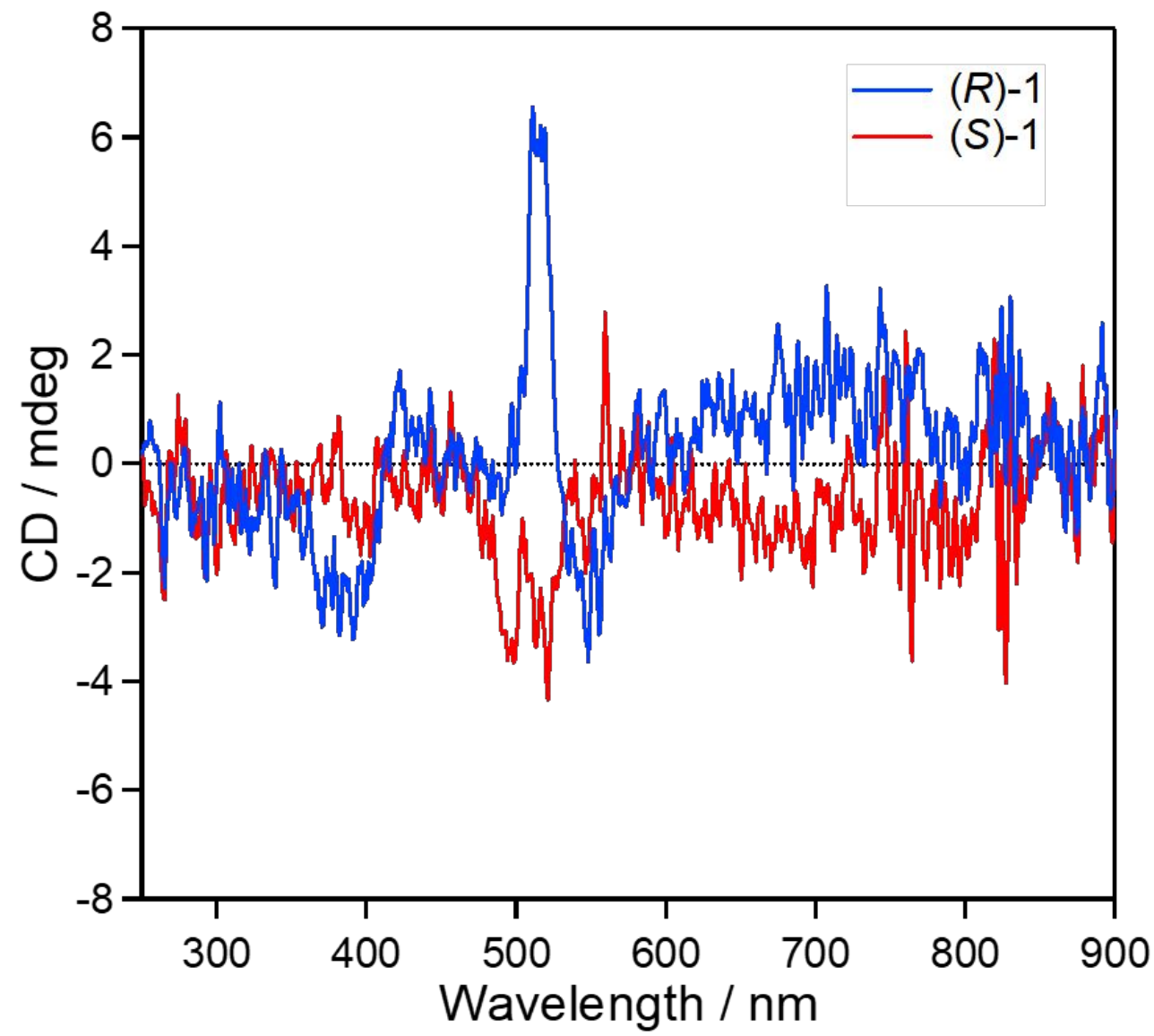

Figure S5. CD spectra of $\boldsymbol{R} \mathbf{- 1}$ and $\boldsymbol{S}-\mathbf{1}$ collected by using thin film technique. 
(a)

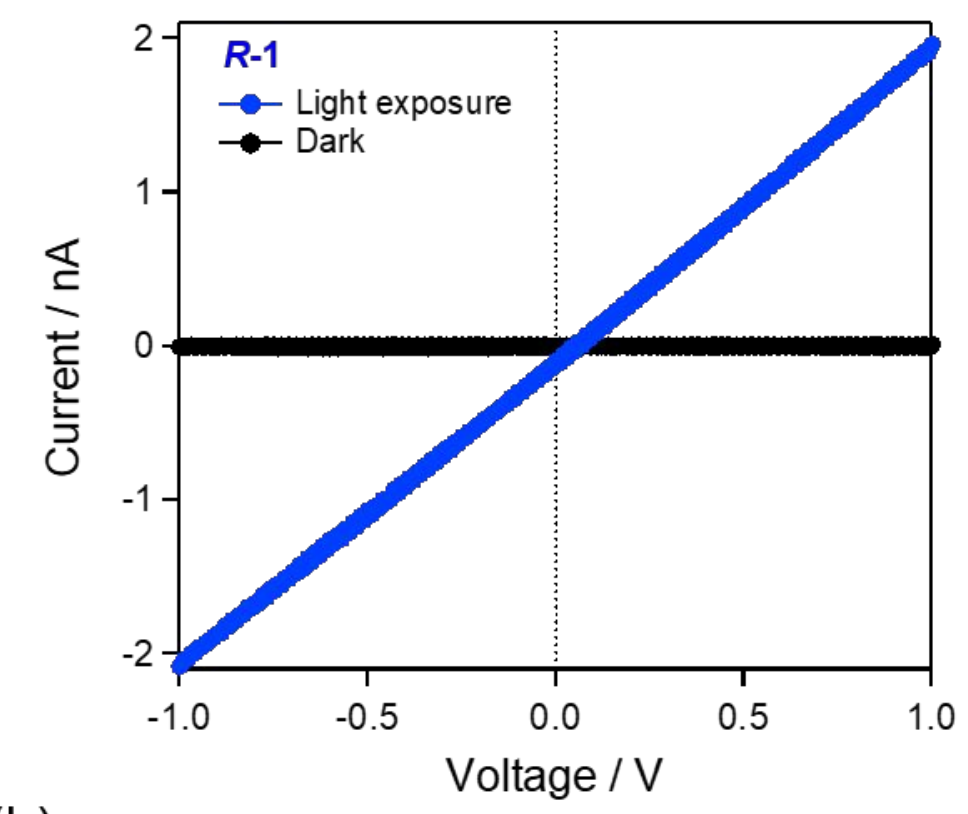

(b)

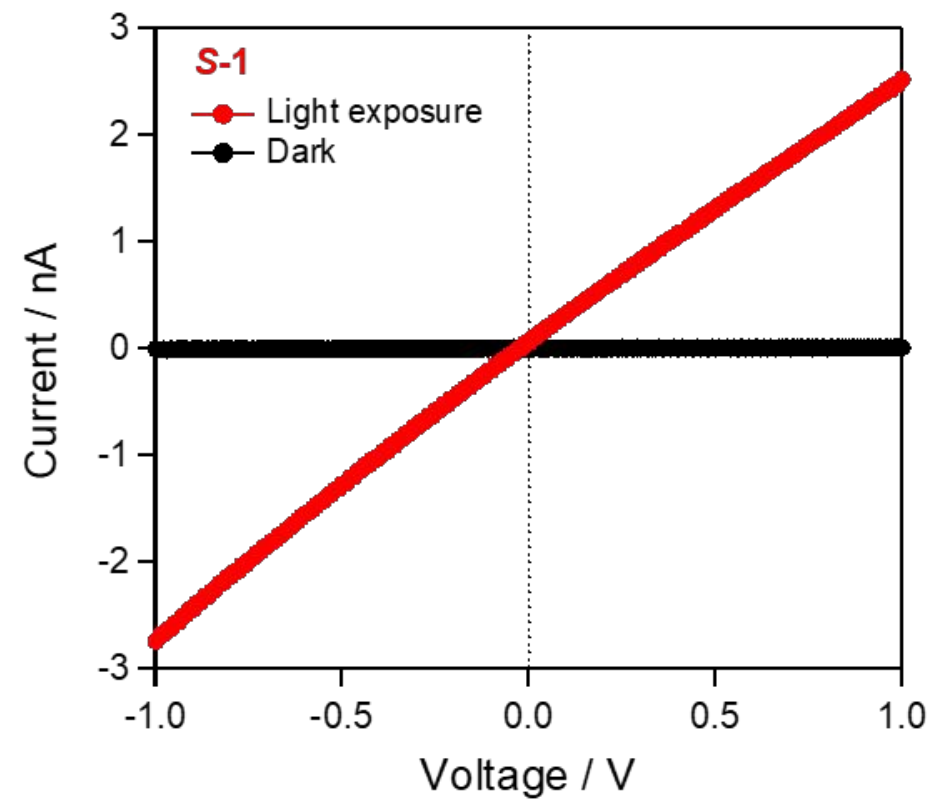

Figure S6. $I-V$ curves measured with and without irradiation of simulated solar white-light for (a) $\boldsymbol{R}-\mathbf{1}$ and (b) $\boldsymbol{S}-\mathbf{1}$. The current is measured along [010] direction. 
(a)

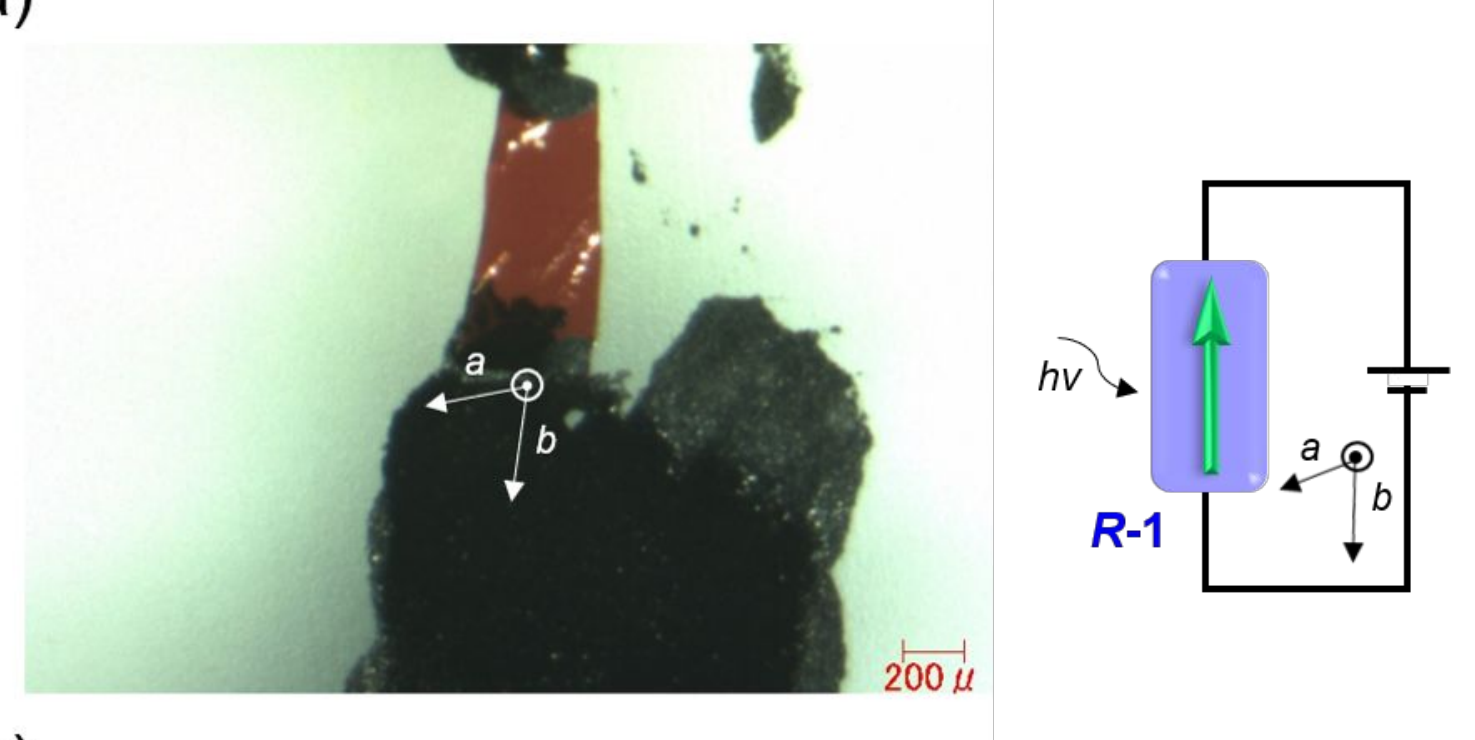

(b)
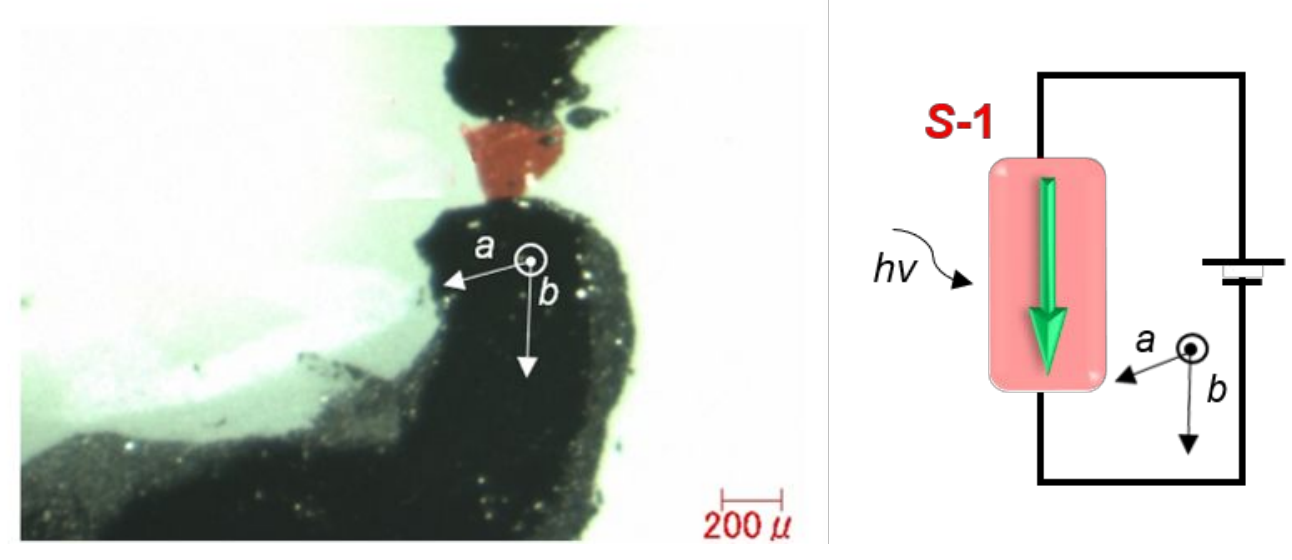

Figure S7. Configurations of single-crystals in the measurement system for (a) $\boldsymbol{R}-\mathbf{1}$ and (b) $\boldsymbol{S}-\mathbf{1}$. $[010]$ is parallel to the electric field. The green arrows represent the electric polarization originated from the electric dipole moments of organic molecule cations $\left(\boldsymbol{P}_{\boldsymbol{m}}\right)$. 


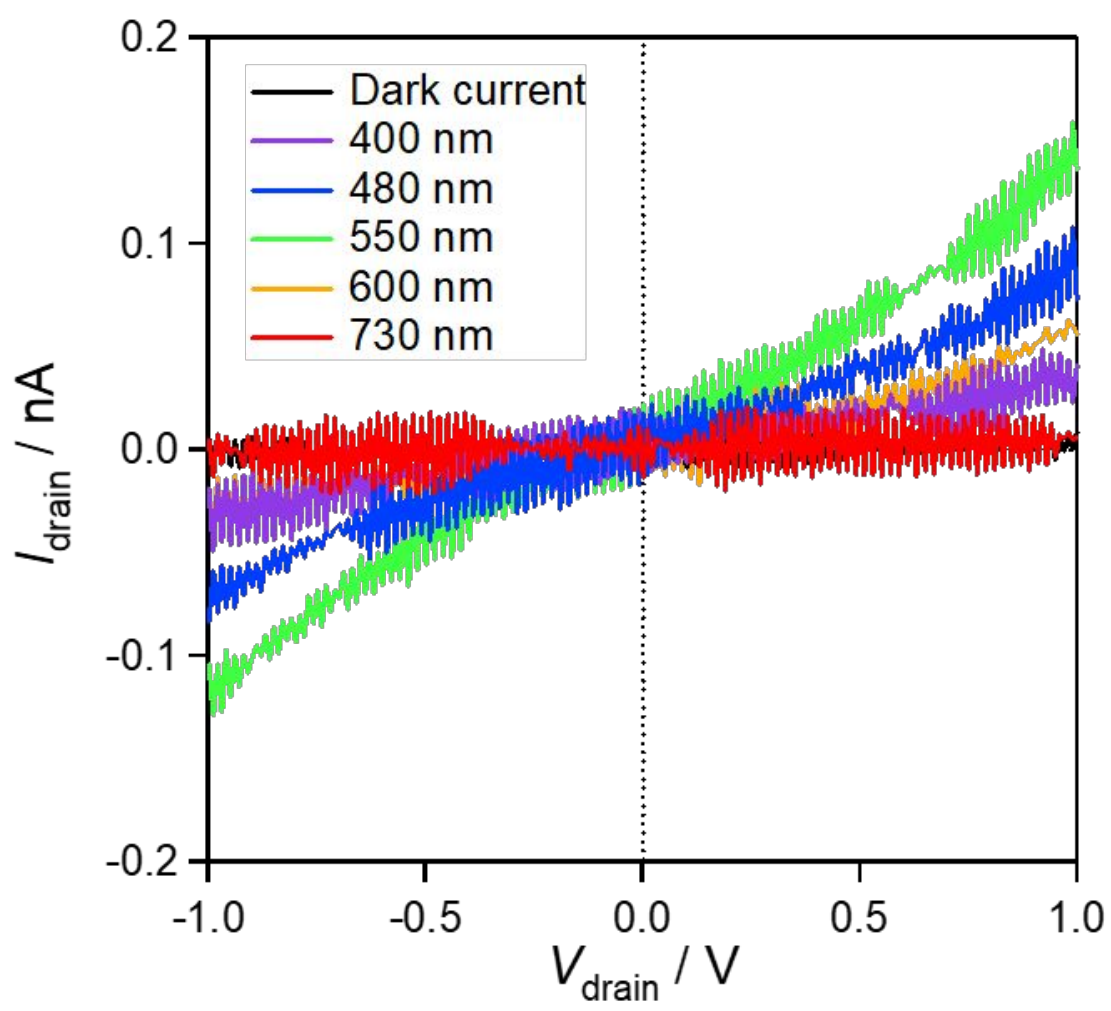

Figure S8. Light wavelength dependence of the photocurrent of $\boldsymbol{R}-\mathbf{1}$. 
(a)

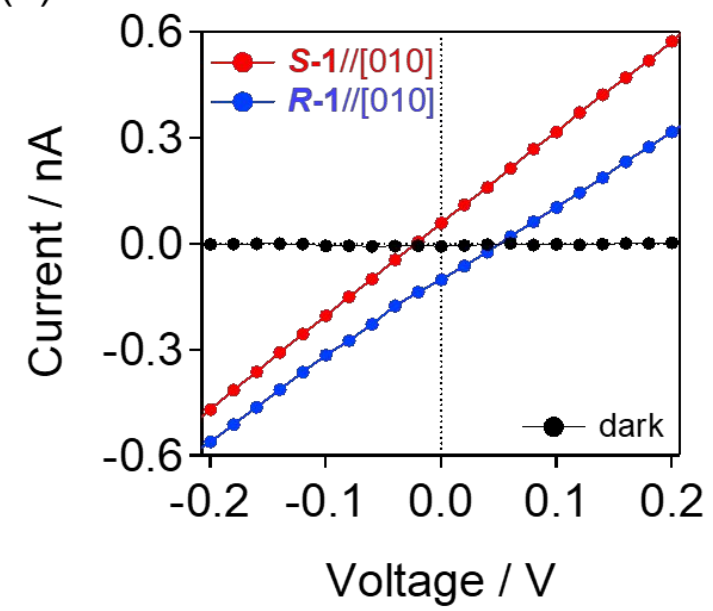

(c)

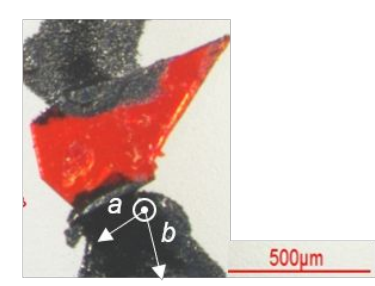

(d)

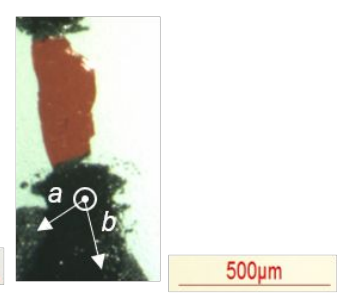

(b)

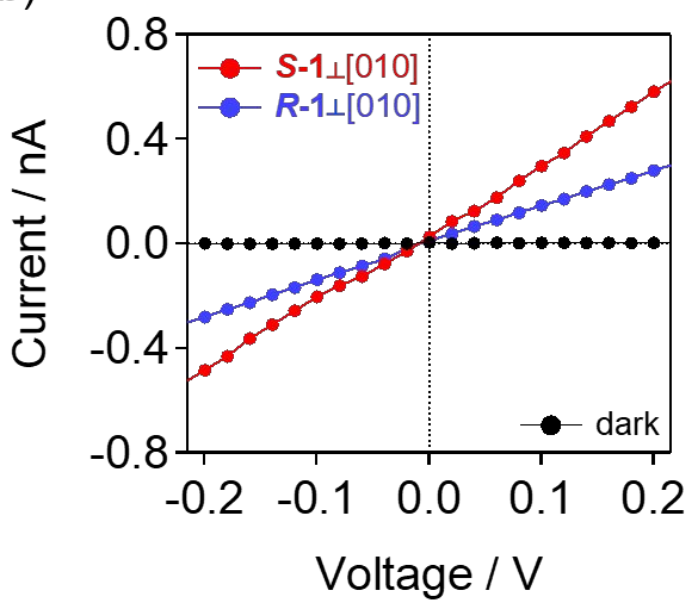

(e)

(f)

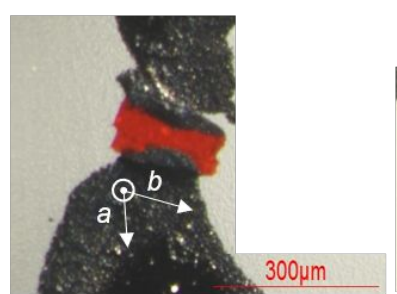

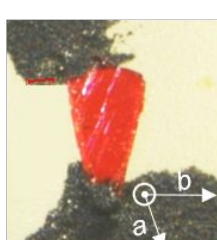

$500 \mu \mathrm{m}$

Figure S9. $I-V$ curves near $0 \mathrm{~V}$ measured in the different devices from those in Figure 4 with irradiation (blue and red circles and lines) and without irradiation (black circles and lines) of simulated solar white-light, which were measured in (a) parallel and (b) perpendicular configurations between [010] and the applied electric field. Configurations of single-crystals in the measurement system for (c) $\boldsymbol{R}-\mathbf{1}$ and (d) $\boldsymbol{S}-\mathbf{1}$ with [010] parallel to the electric field, and (e) $\boldsymbol{R}-\mathbf{1}$ and (f) $S$-1 with [010] perpendicular to the electric field. 


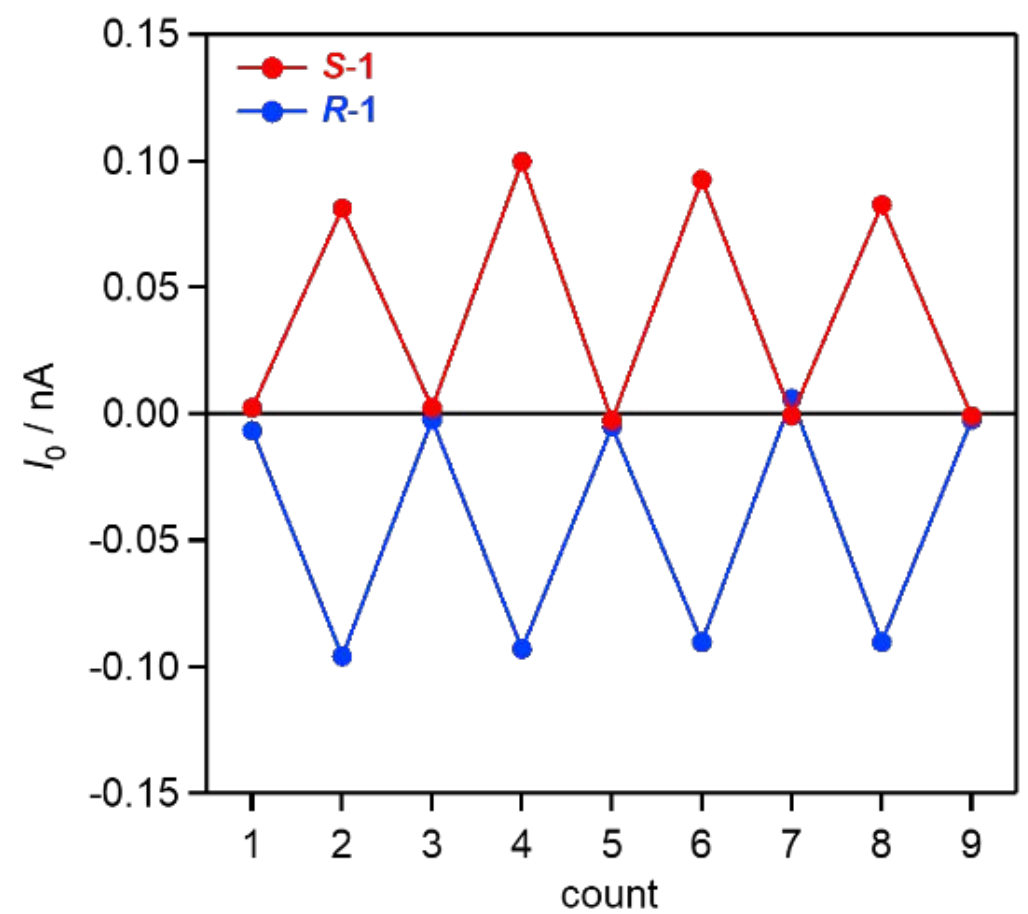

Figure S10. Reproducibility of zero-bias photocurrent $\left(I_{0}\right)$ under solar simulated white-light irradiation for $\boldsymbol{R} \mathbf{- 1}$ and $\boldsymbol{S} \mathbf{- 1}$. 
(a)

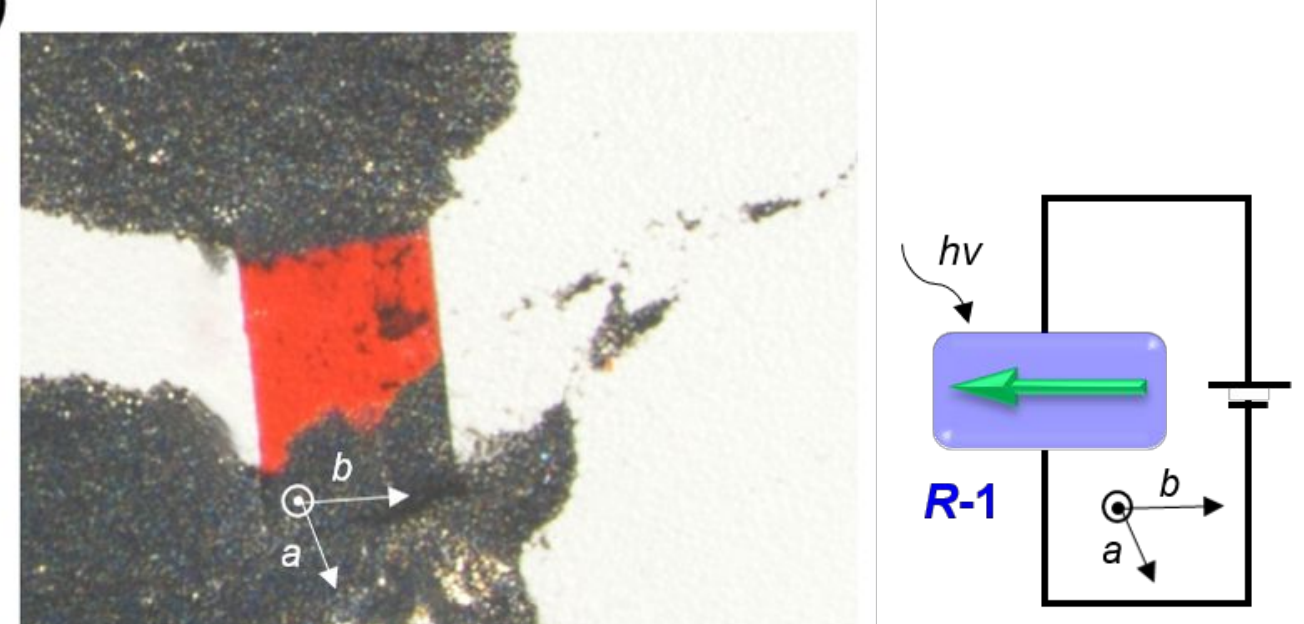

(b)
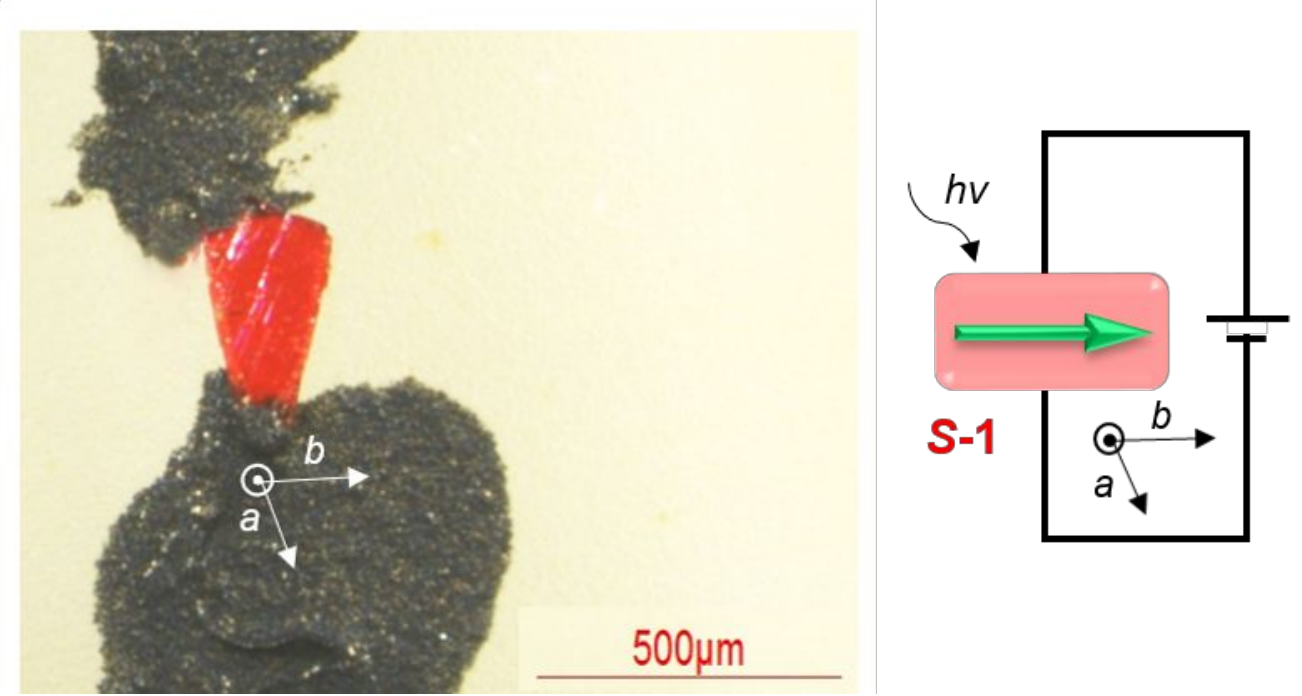

Figure S11. Configurations of single-crystals in the measurement system for (a) $\boldsymbol{R}-\mathbf{1}$ and (b) $\boldsymbol{S}-\mathbf{1}$. [010] is perpendicular to the electric field. The green arrows represent $\boldsymbol{P}_{\boldsymbol{m}}$. 

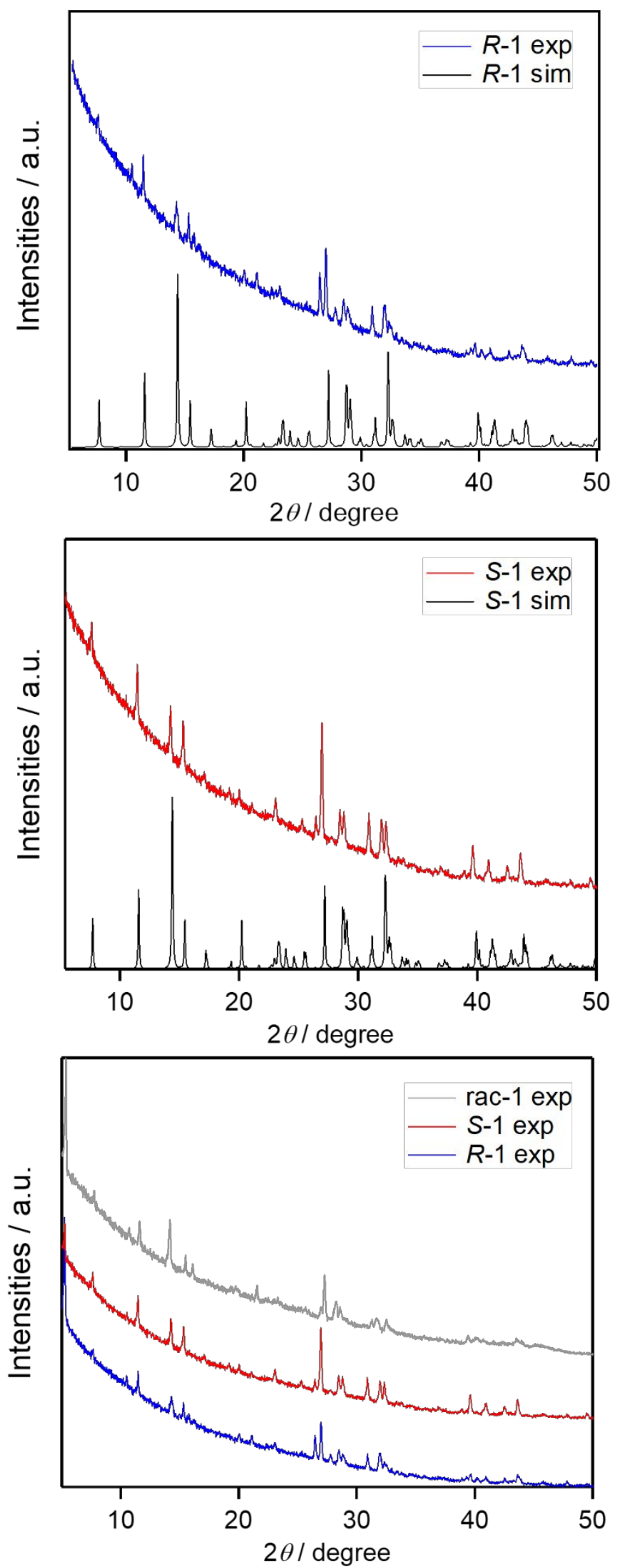

Figure S12. X-ray powder diffraction patterns for $\boldsymbol{R}-1, S-1$, and $\mathbf{r a c}-1$. $R-1 / S-1 /$ rac-1 exp and $\boldsymbol{R}-\mathbf{1} / \boldsymbol{S}-\mathbf{1}$ sim represent the experimental data and the calculated pattern from the structural data obtained by the single-crystal x-ray diffraction analysis. 
(a)

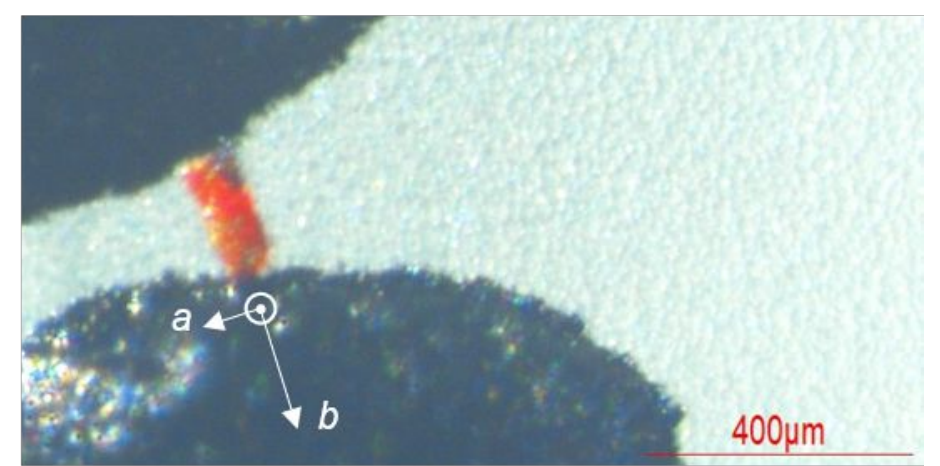

(b)

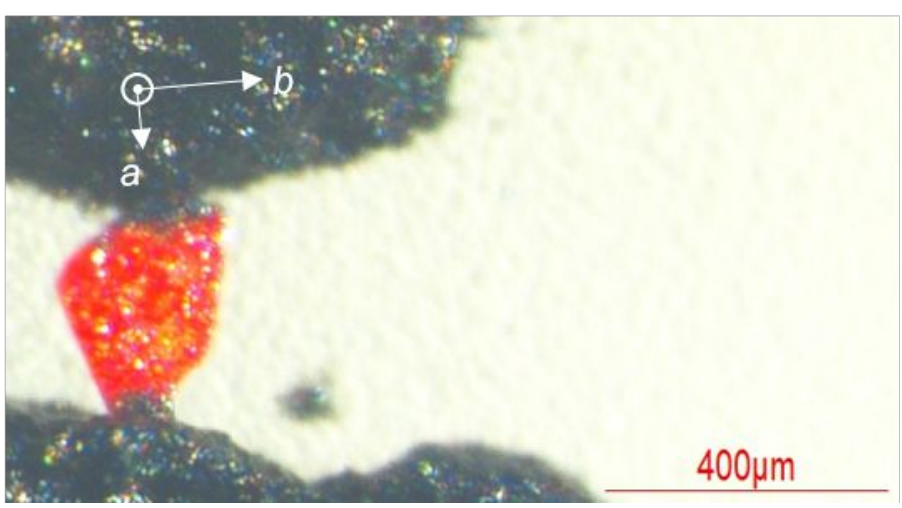

Figure S13. Configurations of single-crystals in the measurement system for rac-1 with [010] (a) parallel and (b) perpendicular to the electric field. The directions for current measurements in PbI-plane are same with those for $\boldsymbol{R} \mathbf{- 1}$ and $\boldsymbol{S} \mathbf{- 1}$. 
Table S1. Noncentrosymmetric point groups allowing BPVE. Chirality introduction results in chiral-only or chiral-polar systems.

\begin{tabular}{ll}
\hline & \multicolumn{1}{c}{ Symmetries allowing BPVE } \\
\hline Chiral and polar & $1,2,3,4,6$ \\
Chiral and nonpolar & $222,23,32,422,622$ \\
Achiral and polar & $\mathrm{m}, \mathrm{mm} 2,3 \mathrm{~m}, 4 \mathrm{~mm}, 6 \mathrm{~mm}$ \\
Achiral and nonpolar & $\overline{4}, \overline{4} 2 \mathrm{~m}, \overline{4} 3 \mathrm{~m}, \overline{6}, \overline{6} \mathrm{~m} 2$ \\
\hline
\end{tabular}


Table S2. Crystallographic data for $R-1, S-1$, and rac-1.

\begin{tabular}{|c|c|c|c|}
\hline & $R-1$ & $S-1$ & rac-1 \\
\hline Formula & $\mathrm{C}_{57} \mathrm{H}_{102} \mathrm{I}_{21} \mathrm{~N}_{9} \mathrm{~Pb}_{6}$ & $\mathrm{C}_{57} \mathrm{H}_{102} \mathrm{I}_{21} \mathrm{~N}_{9} \mathrm{~Pb}_{6}$ & $\mathrm{C}_{57} \mathrm{H}_{102} \mathrm{I}_{21} \mathrm{~N}_{9} \mathrm{~Pb}_{6}$ \\
\hline Formula weight & 4821.69 & 4821.69 & 4821.69 \\
\hline Crystal system & Triclinic & Triclinic & Monoclinic \\
\hline Space group & $P 1$ & $P 1$ & $P 2_{1} / c$ \\
\hline$a(\AA)$ & $12.4050(3)$ & $12.3924(2)$ & $8.8216(3)$ \\
\hline $\mathrm{b}(\AA)$ & $19.6581(6)$ & $19.6540(4)$ & $26.6355(9)$ \\
\hline c $(\AA)$ & $23.3427(7)$ & $23.3396(6)$ & $45.3066(8)$ \\
\hline$\alpha\left(^{\circ}\right)$ & $80.297(3)$ & $80.405(2)$ & 90 \\
\hline$\beta\left({ }^{\circ}\right)$ & $82.671(2)$ & $82.793(2)$ & $92.483(3)$ \\
\hline$\gamma\left({ }^{\circ}\right)$ & $71.668(3)$ & $71.6720(18)$ & 90 \\
\hline$V\left(\AA^{3}\right)$ & $5309.2(3)$ & $5304.5(2)$ & $10635.6(7)$ \\
\hline$Z$ & 2 & 2 & 4 \\
\hline$T(\mathrm{~K})$ & 103 & 103 & 103 \\
\hline$D_{\text {calc }}\left(\mathrm{g} / \mathrm{cm}^{3}\right)$ & 3.016 & 3.019 & \\
\hline$\mu\left(\mathrm{mm}^{-1}\right)$ & 15.638 & 15.652 & \\
\hline Unique reflns [R(int)] & $4224[0.0465]$ & $4224[0.0396]$ & \\
\hline$R_{1}{ }^{[\mathrm{a}]}, w R_{2}^{[\mathrm{b}]}[I>2 \sigma(I)]$ & $0.0859,0.1996$ & $0.0911,0.2369$ & \\
\hline$R_{1}, w R_{2}$ (all data) & $0.1073,0.2164$ & $0.0970,0.2424$ & \\
\hline Flack parameter $(x)$ & $0.145(12)$ & $0.154(9)$ & \\
\hline CCDC No. & 1936623 & 1936624 & \\
\hline
\end{tabular}

[a] $R_{1}=\left(\Sigma|| F_{\mathrm{O}}|-| F_{\mathrm{C}}||\right) / \Sigma\left|F_{\mathrm{O}}\right|,[\mathrm{b}] w R_{2}=\left\{\Sigma\left[w\left(F_{\mathrm{O}}^{2}-F_{\mathrm{C}}^{2}\right)^{2}\right] / \Sigma\left[w\left(F_{\mathrm{O}}^{2}\right)\right]^{2}\right\}^{1 / 2}$ 
(1) CrysAlisPro 1.171.38.43, Rigaku Corporation, Tokyo, 2015.

(2) Burla, M. C.; Caliandro, R.; Camalli, M.; Carrozzini B.; Cascarano, G. L.; Giacovazzo, C.; Mallamo, M.; Mazzone, A.; Polidori, G.; Spagna, R., SIR2011, J. Appl. Cryst. 2012, 45, 357.

(3) CrystalStructure 4.1: Crystal Structure Analysis Package, Rigaku Corporation, Tokyo, 2000-2014.

(4) CrystalClear-SM 1.4.0 SPI, Rigaku Corporation, Tokyo, 1998-2008.

(5) Frisch, M. J.; Trucks, G. W.; Schlegel, H. B.; Scuseria, G. E.; Robb, M. A.; Cheeseman, J. R.; Scalmani, G.; Barone, V.; Mennucci, B.; Petersson, G. A.; Nakatsuji, H.; Caricato, M. ; Li, X.; Hratchian, H. P.; Izmaylov, A. F.; Bloino, J.; Zheng, G.; Sonnenberg, J. L.; Hada, M.; Ehara, M.; Toyota, K.; Fukuda, R.; Hasegawa, J.; Ishida, M.; Nakajima, T.; Honda, Y.; Kitao, O.; Nakai, H.; Vreven, T.; Montgomery, Jr., J. A.; Peralta, J. E.; Ogliaro, F.; Bearpark, M.; Heyd, J. J.; Brothers, E.; Kudin, K. N.; Staroverov, V. N.; Kobayashi, R.; Normand, J.; Raghavachari, K.; Rendell, A.; Burant, J. C.; Iyengar, S. S.; Tomasi, J.; Cossi, M. Rega, N.; Millam, J. M.; Klene, M.; Knox, J. E.; Cross, J. B.; Bakken, V.; Adamo, C.; Jaramillo, J.; Gomperts, R.; Stratmann, R. E.; Yazyev, O.; Austin, A. J.; Cammi, R.; Pomelli, C.; Ochterski, J. W.; Martin, R. L.; Morokuma, K.; Zakrzewski, V. G.; Voth, G. A.; Salvador, P.; Dannenberg, J. J.; Dapprich, S.; Daniels, A. D.; Farkas, Ö.; Foresman, J. B.; Ortiz, J. V.; Cioslowski, J.; Fox, D. J., Gaussian 09, Revision B.01, Gaussian, Inc., Wallingford CT, 2009. 